Analytical Methods

\title{
Simple method to reduce the cyanogen content of gari made from cassava
}

\author{
J. Howard Bradbury *, Ian C. Denton \\ Botany and Zoology, Research School of Biology, Australian National University, Canberra, ACT 0200, Australia
}

\section{A R T I C L E I N F O}

\section{Article history:}

Received 25 March 2009

Received in revised form 15 January 2010

Accepted 1 May 2010

\section{Keywords:}

Cassava

Gari

Cassava flour

Cyanogens

Acetone cyanohydrin

Tropical ataxic neuropathy

\begin{abstract}
A B S T R A C T
The lactic acid content of gari, was determined by $\mathrm{pH}$ titration to be about $10 \mathrm{~g}$ lactic acid $/ \mathrm{kg}$ gari. As the size of the gari particles increased from 400 to $>1000 \mu \mathrm{m}$ their total cyanide content increased from 5 to $21 \mathrm{ppm}$. The acetone cyanohydrin content of gari samples exposed to ambient laboratory conditions of temperature and relative humidity gradually decreased by $58 \%$ in 38 weeks whereas linamarin in cassava flour is $100 \%$ stable for 6 months. Cyanogens could not be removed from wet gari samples at 30 or $50{ }^{\circ} \mathrm{C}$ and were only slowly removed by repeated heating at $100{ }^{\circ} \mathrm{C}$ and rewetting. By mixing equal weights of gari ( $\mathrm{pH} 4.1$ ) and low cyanide cassava flour ( $\mathrm{pH}$ 6.5), wetting and heating at $50^{\circ} \mathrm{C}$ for $5 \mathrm{~h}$, the cyanide content was reduced by about one half. Wetting a gari/flour (1:1) sample with 1.5 times its weight of water and standing in a $1 \mathrm{~cm}$ thick layer in the sun for $4 \mathrm{~h}$ reduced the cyanide content by about one half. This treated mixture may be cooked to prepare stiff porridge with lowered cyanide content, and may help reduce tropical ataxic neuropathy in West Africa.
\end{abstract}

(C) 2010 Elsevier Ltd. All rights reserved.

\section{Introduction}

Cassava is the staple food of tropical Africa and its production and consumption is increasing rapidly in order to feed a rapidly increasing population (Nhassico, Muquingue, Cliff, Cumbana, \& Bradbury, 2008). Cassava is easy to propagate from stem cuttings, yields well in poor soils without fertilizer and is drought resistant, because the plant is sustained during drought by its tuberous roots, which are also a reserve source of food. The roots are very starchy and the leaves are a good source of protein. Cassava produces two cyanogenic glucosides, linamarin and a small amount of lotaustralin (methyl linamarin) that are hydrolysed to give a cyanohydrin and glucose, catalysed by linamarase. The cyanohydrin decomposes spontaneously above pH 5 (White, Mc Mahon, \& Sayre, 1994), to liberate poisonous hydrogen cyanide which is a danger to human health.

A new processing method to remove cyanogens from cassava flour involves mixing dry flour with water and leaving the wet flour in a thin layer in the shade for $5 \mathrm{~h}$ or for $2 \mathrm{~h}$ in the sun to allow the catalysed breakdown of linamarin to hydrogen cyanide. The wet flour is used for cooking the same day. This gives a threeto sixfold reduction in total cyanide content of cassava flour (Bradbury, 2006; Bradbury \& Denton, 2010; Cumbana, Mirione, Cliff, \& Bradbury, 2007). The method was successfully field-tested in Mozambique and is being introduced also in Tanzania (Nhassico et al., 2008) and Democratic Republic of Congo (Karumba, Denton, \& Bradbury, 2009).

\footnotetext{
* Corresponding author.

E-mail address: Howard.Bradbury@anu.edu.au (J.H. Bradbury).
}

In West Africa cassava is processed predominantly by grating the peeled root and allowing fermentation in a sack for about 3 days, followed by expression of the cyanogenic liquid and heating with stirring in a metal pan over a wood fire to give a gritty, roasted product called gari. This removes much more cyanogens than the various methods used to produce cassava flour in Eastern, Southern and Central Africa (Cardoso et al., 2005). Thus, the average total cyanide content of cassava flour in a good season in Mozambique is about 45 ppm (Cardoso, Ernesto, Cliff, Egan, \& Bradbury, 1998) and of gari in West Africa is about $20 \mathrm{ppm}$ (Cardoso et al., 2005). The WHO safe level for cyanogens in cassava flour is $10 \mathrm{ppm}$ (FAO/WHO, 1991).

Under drought conditions the total cyanide content of flour is more than doubled and this leads to cyanide poisoning and outbreaks of konzo (Howlett, Brubaker, Mlingi, \& Rosling, 1990) in various countries of Eastern and Central Africa. Tropical ataxic neuropathy (TAN) occurs in West Africa (particularly Nigeria), Tanzania, Uganda, Kenya, West Indies and South India (Osuntokun 1981, 1994) and probably results from continuous intake over years of cyanogens from a monotonous diet of cassava. TAN is a progressive neurological disease that causes unsteady walking, loss of sensation in hands, blindness, deafness and weakness. Recent studies have thrown doubt on the linkage of TAN with long term cyanide intake from cassava (Oluwole et al., 2003), but recent work from India (Madhusudanan, Menon, Ummer, \& Radhakrishnanan, 2008) supports earlier studies by Osuntokun (1994) of a linkage.

The major cyanogen present in gari is acetone cyanohydrin (Bradbury, 2009; Onabolu, Oluwole, Rosling, \& Bokanga, 2002), whereas that present in cassava flour is linamarin. Since the total cyanide content of cassava flour is reduced three- to sixfold using 
the wetting method (Bradbury, 2006; Cumbana et al., 2007) it might be expected that a similar reduction would occur with gari. Unfortunately the $\mathrm{pH}$ of gari is about 4.1, due to lactic acid fermentation that occurs during processing (Obilie, Tano-Debrah, \& AmoaAwua 2004), and acetone cyanohydrin is considered to be stable under these conditions (White et al., 1994). In this paper we have initially studied various properties of gari and different possible methods to remove cyanogens from gari. These initial studies showed the way forward to development of a method by which the $\mathrm{pH}$ of the gari is increased by mixing with flour, wetting with water and drying in the sun. This reduces the total cyanide content of the gari/flour mixture by one half. If implemented in West Afri$\mathrm{ca}$, this would reduce the cyanide intake of people consuming gari and may reduce the incidence of TAN.

\section{Materials and methods}

\subsection{Materials}

Five different samples of commercial gari were obtained from local markets in Maputo, Mozambique, and were stored in a deep freeze at $-20^{\circ} \mathrm{C}$, where they are stable indefinitely. Cassava flour samples were produced from cassava roots grown in a glass house in Canberra, some of which had been used in earlier studies (Bradbury, 2006). Thermochron iButton, model DS1922L-F5 was used as a temperature data logger with a range of temperatures -40 to $85^{\circ} \mathrm{C}$, and produced by Embedded Data Systems, Dallas, Texas, USA.

\subsection{Methods}

\subsubsection{Initial measurements of the properties of gari samples and} cyanogen loss from gari

2.2.1.1. Measurement of acid content of gari. A sample of gari 2 $(10 \mathrm{~g})$ was dispersed in $50 \mathrm{~mL}$ water and titrated with $0.100 \mathrm{M}$ $\mathrm{NaOH}$ in a $250-\mathrm{mL}$ beaker fitted with a magnetic stirrer using a Beckman $\mathrm{pH}$ metre. The $\mathrm{pH}$ metre was calibrated with standard buffers at $\mathrm{pH} 4.00$ and 7.00. The $\mathrm{pH}$ increased slowly after addition of each $1.00 \mathrm{~mL}$ of $\mathrm{NaOH}$ from a burette and became constant after $<1 \mathrm{~min}$. Titration was continued up to $\mathrm{pH} 9$ and was repeated with gari 5.

2.2.1.2. Total cyanide content of sieved fractions of gari. Samples $(10 \mathrm{~g})$ of gari 2 , gari 3 and gari 5 were sieved separately by hand using a stack of Endicott sieves of sizes 425, 850 and $1000 \mu \mathrm{m}$ into fractions $<425 \mu \mathrm{m}$ (very fine), $425-850 \mu \mathrm{m}$ (fine), $850-1000 \mu \mathrm{m}$ (medium) and $>1000 \mu \mathrm{m}$ (coarse). The weights of each of the fractions was recorded. In the coarse fraction there were a number of much larger pieces, irregular aggregates of 3-10 mm diameter. These aggregates were picked out using tweezers from the coarse fraction. For total cyanide analysis, duplicate $100 \mathrm{mg}$ samples were placed in plastic vials, a linamarase/buffer paper was added, followed by $1 \mathrm{~mL}$ of $1.0 \mathrm{M}$ phosphate buffer at $\mathrm{pH} 6.8$, a sensitive picrate paper and a lid. The vial was maintained at $30^{\circ} \mathrm{C}$ overnight, the $1 \mathrm{~cm}^{2}$ picrate paper was separated from the plastic strip and the paper eluted for $30 \mathrm{~min}$ with $0.50 \mathrm{~mL}$ of distilled water. The absorbance $(A)$ of the solution was measured using $2 \mathrm{~mm}$ cuvettes in a Beckman DU 540 spectrometer in the direct reading mode, against a blank solution prepared from a $1 \mathrm{~cm}^{2}$ picrate paper not exposed to $\mathrm{HCN}$ and eluted with $0.50 \mathrm{~mL}$ water. The total cyanide content in $\mathrm{mg} \mathrm{HCN}$ equivalents $/ \mathrm{kg}$ sample $=\mathrm{ppm}$ was calculated by the equation, $\mathrm{ppm}=A \times 45.7$ (Bradbury, 2009).

2.2.1.3. Loss of cyanide from gari samples under ambient conditions. Samples (about $5 \mathrm{~g}$ ) of each of the five gari samples were placed in small plastic dishes at ambient conditions of temperature and relative humidity, exposed to the air for 38 weeks and the total cyanide content monitored as a function of time, see Section 2.2.1.2.

2.2.1.4. Attempted loss of cyanide from gari with multiple wetting/ heating at $100^{\circ} \mathrm{C}$. Two gari $5(2 \mathrm{~g})$ samples were taken in weighed $100 \mathrm{~mL}$ beakers, $2 \mathrm{~mL}$ of water added to 1 and $2 \mathrm{~mL}$ of $1 \mathrm{M}$ phosphate buffer ( $\mathrm{pH}$ 6.9) to the other. After mixing, duplicate samples were withdrawn for total cyanide analysis and the beakers weighed and heated for $30 \mathrm{~min}$ at $100{ }^{\circ} \mathrm{C}$ in an oven. The beakers were removed, weighed, water added with mixing to give the same weight as before the heating, and duplicate $100 \mathrm{mg}$ samples taken for total cyanide analysis. The beakers were again weighed, heated at $100{ }^{\circ} \mathrm{C}$ for $30 \mathrm{~min}$ and the process repeated a second time. This process was repeated five times in all making a total heating time at $100{ }^{\circ} \mathrm{C}$ of $2.5 \mathrm{~h}$. At the end of the cycle $0.5 \mathrm{~g}$ of the wet flour samples were mixed with $2 \mathrm{~mL}$ water, the $\mathrm{pH}$ of the solutions measured and found to be 4.3 and 6.9, respectively.

2.2.1.5. Loss of total cyanide from wet gari samples with or without $p H$ adjustment. Gari (2 g) was mixed with either 2 or $3 \mathrm{~mL}$ of water or with $3 \mathrm{~mL}$ of $1.0 \mathrm{M}$ buffer in a weighed $100 \mathrm{~mL}$ beaker. Above $\mathrm{pH} 6$, 1.0 M phosphate buffer was used and for $\mathrm{pH} 4-6,1.0 \mathrm{M}$ citrate buffer solutions were used. These were prepared from a $1 \mathrm{M}$ citrate buffer by adjustments of $\mathrm{pH}$ using conc. $\mathrm{HCl}$ or $\mathrm{NaOH}$ solutions as required. Duplicate $100 \mathrm{mg}$ samples were taken for total cyanide analysis and a $1.0 \mathrm{~g}$ sample of wet gari was added to $2 \mathrm{~mL}$ water for $\mathrm{pH}$ measurement. The wet gari sample was heated in an oven at 30 or $50^{\circ} \mathrm{C}$ for $5 \mathrm{~h}$, after which water was added with mixing to give the same weight as at the beginning. Duplicate $100 \mathrm{mg}$ samples were removed for total cyanide analysis (Section 2.2.1.2) and a $1.0 \mathrm{~g}$ sample for $\mathrm{pH}$ measurement.

\subsubsection{Loss of cyanide from wet gari, gari/flour and flour samples}

Gari ( $1 \mathrm{~g}$ ) was mixed with flour $(1 \mathrm{~g})$ and $3 \mathrm{~mL}$ water was added with mixing in a weighed $100 \mathrm{~mL}$ beaker. Samples of flour $(2 \mathrm{~g})$ or gari $(2 \mathrm{~g})$ were also mixed with $3 \mathrm{~mL}$ water in a weighed $100 \mathrm{~mL}$ beaker. Duplicate $100 \mathrm{mg}$ samples were withdrawn for total cyanide analysis and $0.5 \mathrm{~g}$ for $\mathrm{pH}$ measurement. The mixed wet sample was heated at 30 or $50^{\circ} \mathrm{C}$ in an oven for $5 \mathrm{~h}$, the beaker weighed and water added to replace that lost by evaporation and mixed well. Duplicate $100 \mathrm{mg}$ samples were taken for total cyanide analysis and $0.5 \mathrm{~g}$ for $\mathrm{pH}$ measurement (Section 2.2.1.4).

\subsubsection{Cyanide loss from wet gari and gari/flour samples treated in the sun}

Gari and gari/cassava flour (1:1) samples were placed in small weighed glass Petri dishes, mixed dry and wetted with 1.5 times their weight of water. Sample sizes were either $5 \mathrm{~g}$ gari, $5 \mathrm{~g}$ flour and $15 \mathrm{~g}$ water or $1 \mathrm{~g}$ gari, $1 \mathrm{~g}$ flour and $3 \mathrm{~g}$ water. After mixing, duplicate $100 \mathrm{mg}$ samples were withdrawn for cyanide analysis (see Section 2.2.1.2). The Petri dish was placed on a concrete slab in the sun for $4 \mathrm{~h}$. In some cases an iButton was placed in the dish to monitor the temperature of the wet flour over the course of the experiment. The iButton was either directly exposed to the sun or just covered by about $5 \mathrm{~mm}$ of the wet flour. After $4 \mathrm{~h}$ the sample was weighed, water added to replace that lost by evaporation with mixing and duplicate $100 \mathrm{mg}$ samples taken for cyanide analysis and $0.5 \mathrm{~g}$ for measurement of $\mathrm{pH}$. In several experiments the weighed gari/flour samples were heated in the sun for $2 \mathrm{~h}$ followed by addition of water and then heated for another $2 \mathrm{~h}$ in the sun followed by addition of water, mixing and cyanide analysis, but this gave similar results to one period of heating for $4 \mathrm{~h}$. Experiments were also made with two UV sources, a Sunlamp and a Spectrolin- 
ker Model XL-1500 UV crosslinker (Spectronics Corporation), operating at $254 \mathrm{~nm}$.

\section{Results and discussion}

Since the aim of this study was to develop a simple method to remove cyanogens from gari, it was necessary to do a number of initial experiments on the properties of gari and on possible methods to remove cyanogens from gari. These initial experiments (see Sections 2.2.1.1 to 2.2.1.5), carried out on one or more of the five gari samples, showed the way forward and allowed development of the final method, which was checked out with all five gari samples and two flour samples of low total cyanide content.

\subsection{Acid content of gari}

Cassava flour samples dispersed in water have a pH of about 6.5 and are buffered by citrate, malate and succinate anions. The total amount of these anions in fresh cassava roots (which contain ca. $63 \%$ moisture) is about $10 \mathrm{~g} / \mathrm{kg}$ fresh root (Bradbury \& Holloway, 1988), and hence the amount present in cassava flour made by sun drying (which contains ca. 9\% moisture) would be ca. $24 \mathrm{~g} / \mathrm{kg}$ fresh flour. In gari the $\mathrm{pH}$ has been reduced to $4.1-4.2$ by lactic acid fermentation during preparation (Obilie et al., 2004; Sokari \& Karibo, 1996). By titration of gari with $\mathrm{NaOH}$ up to $\mathrm{pH} 6.5$, one can calculate the amount of lactic acid in the gari sample.

Gari 2 and gari 5 were titrated with $0.1 \mathrm{M} \mathrm{NaOH}$ (see Section 2.2.1.1). There was a slow increase of $\mathrm{pH}$ from 4.1 up to 5.4 followed by a more rapid increase of $\mathrm{pH}$ up to 6.5 and then another slow increase up to $\mathrm{pH} 7.0$. The titration was continued up to $\mathrm{pH}$ 9. The $10 \mathrm{~g}$ samples of gari 2 and gari 5 in water required 10.0 and $12.6 \mathrm{~mL}$ of $0.100 \mathrm{M} \mathrm{NaOH}$, respectively, to raise the $\mathrm{pH}$ to 6.5. This corresponds to $9.0 \mathrm{~g}$ lactic acid/ $\mathrm{kg}$ gari 2 and $11 \mathrm{~g}$ lactic acid/kg gari 5 . On average the lactic acid content of gari is about $10 \mathrm{~g} / \mathrm{kg}$ gari, which is much less than the total value of the other organic acid anions present in cassava flour and probably also in gari.

\subsection{Size distribution and total cyanide content of gari particles}

Gari was separated into fractions by sieving and each was analysed for total cyanide content (see Section 2.2.1.2). Similar results were obtained for each gari sample and mean values and standard deviations are recorded in Table 1 . The bulk of the gari (62.6\%) is in the coarse fraction $(>1000 \mu \mathrm{m})$ and includes aggregates. Aggregates are particles that were probably fused together during the final roasting of the gari, that involves heating in a metal dish over a wood fire and stirring with a wooden spoon. This roasting volatilises water and hydrogen cyanide ( $\mathrm{HCN}$ ) from the wet solid, partially decomposes acetone cyanohydrin to $\mathrm{HCN}$ and also gelatinises some starch granules at $60-70^{\circ} \mathrm{C}$, which also fuses particles together to form aggregates. The roasting process gives gari a gritty,

Table 1

Size distribution and total cyanide content of gari fractions.

\begin{tabular}{llcc}
\hline $\begin{array}{l}\text { Designation of } \\
\text { fractions }\end{array}$ & $\begin{array}{l}\text { Size of particles } \\
(\mu \mathrm{m})\end{array}$ & $\begin{array}{l}\text { Total cyanide } \\
\text { content }(\mathrm{ppm})^{\mathrm{a}}\end{array}$ & $\begin{array}{c}\text { \% of total } \\
\text { sample }^{\mathrm{a}}\end{array}$ \\
\hline Very fine & $<425$ & $4.6 \pm 3.2$ & $0.8 \pm 0.6$ \\
Fine & $425-850$ & $7.4 \pm 3.3$ & $21.0 \pm 7.6$ \\
Medium & $850-1000$ & $15.3 \pm 3.2$ & $15.6 \pm 2.5$ \\
Coarse & $>1000$ & $18.0 \pm 2.1$ & $62.6 \pm 10.5$ \\
Aggregates $^{\mathrm{b}}$ & Large pieces $^{\mathrm{b}}$ & $21.2 \pm 2.9$ & \\
\hline
\end{tabular}

\footnotetext{
${ }^{\text {a }}$ Mean values and standard deviations are for gari samples 2, 3 and 5 .

b Aggregates of about $5 \mathrm{~mm}$ diameter which were hand picked from the coarse fraction.
}

hard surface and it is quite difficult to grind it up into finer particles in a pestle and mortar, in contrast to cassava flour which is soft and fluffy and easy to grind.

It is noteworthy that the total cyanide content of gari particles increases with increasing particle size, such that the cyanide content of aggregates is about 4.5 times as large as that of the very fine particles. This is probably due to residual acetone cyanohydrin and $\mathrm{HCN}$ escaping most easily from the very fine particles and not so readily from the gelatinised coarse particles and aggregates. With cassava flour particles there is no difference in cyanide content between coarse and fine flour particles (Bradbury, 2006).

\subsection{Loss of cyanide from gari under ambient conditions}

The total cyanide content was followed under ambient laboratory conditions of temperature and relative humidity over a period of 38 weeks for the five gari samples. Acetone cyanohydrin (85\%) is the major cyanogen present and the remainder is linamarin (Bradbury, 2009). The percentage total cyanide remaining for each gari sample was averaged and the results are shown in Fig. 1. There is a steady slow decline in total cyanide content with time and $42 \%$ still remains after 38 weeks. A moisture determination on the five gari samples by oven drying at $80^{\circ} \mathrm{C}$ to constant weight, gave $9.5 \%$ moisture. This loss of cyanide is very much less than that obtained by Onabolu et al. (2002), who found complete loss of cyanogen in 4 weeks at a slightly higher moisture content, 8.7-13\%. Our ambient laboratory temperature averaged about $20^{\circ} \mathrm{C}$, which was lower than the tropical conditions of Onabolu et al. (2002). The slightly higher moisture content and higher temperature and relative humidity used by Onabolu et al. (2002) may explain the difference in results between their work and ours. We conclude that the acetone cyanohydrin remaining in gari at $\mathrm{pH} 4.1-4.2$ is surprisingly stable ( $42 \%$ remaining after 38 weeks), but is much less stable than linamarin in cassava flour, where $100 \%$ remained after 6 months (Bradbury, 2006).

\subsection{Effect of temperature and $\mathrm{pH}$ on cyanide removal from wet gari}

The data of White et al. (1994) show increased instability of acetone cyanohydrin as temperature is increased. Accordingly, two gari samples were wet with water which gave a $\mathrm{pH}$ of 4.3 and $1.0 \mathrm{M}$ buffer which gave a pH of 6.9 , heated at $100{ }^{\circ} \mathrm{C}$ for $30 \mathrm{~min}$ and then wet with water and reheated again four times over, see Section 2.2.1.4. The results in Fig. 2 show a slow linear drop in total cyanide content in gari at $\mathrm{pH} 4.3$. This could perhaps be due to evaporation of acetone cyanohydrin (BP $82{ }^{\circ} \mathrm{C}$ at $25 \mathrm{~mm}$ $\mathrm{Hg}$ pressure) from the wet gari, but is more likely due to decomposition of acetone cyanohydrin to acetone and $\mathrm{HCN}$ at $100^{\circ} \mathrm{C}$. The very slow loss of acetone cyanohydrin from wet gari at $100{ }^{\circ} \mathrm{C}$ at $\mathrm{pH} 4.3$ shows that swelling with water and elevated temperature is not a good method to remove acetone cyanohydrin from wet gari.

However, increasing the $\mathrm{pH}$ of wet gari to 6.9 with phosphate buffer at the beginning of the experiment, produced a 75\% loss of cyanide in a single $30 \mathrm{~min}$ treatment at $100{ }^{\circ} \mathrm{C}$ (Fig. 2). These initial experiments show that acetone cyanohydrin in gari is removed at $100{ }^{\circ} \mathrm{C}$ if the $\mathrm{pH}$ is increased from 4.3 to 6.9 , and in the next section we study in detail the effect of $\mathrm{pH}$.

\subsection{Effect of $\mathrm{pH}$ on cyanide loss from wet gari}

Gari samples were mixed either with water to obtain $\mathrm{pH} 4.2$ or with $1.0 \mathrm{M}$ buffers of $\mathrm{pH}$ from $4.5-6.8$ and heated at 30 or $50{ }^{\circ} \mathrm{C}$ for $5 \mathrm{~h}$, with water replacement/mixing at the end of the heating period. The loss of total cyanide was monitored and pH checked (Section 2.2.1.5). Both curves in Fig. 3 show the reduction in \% total 


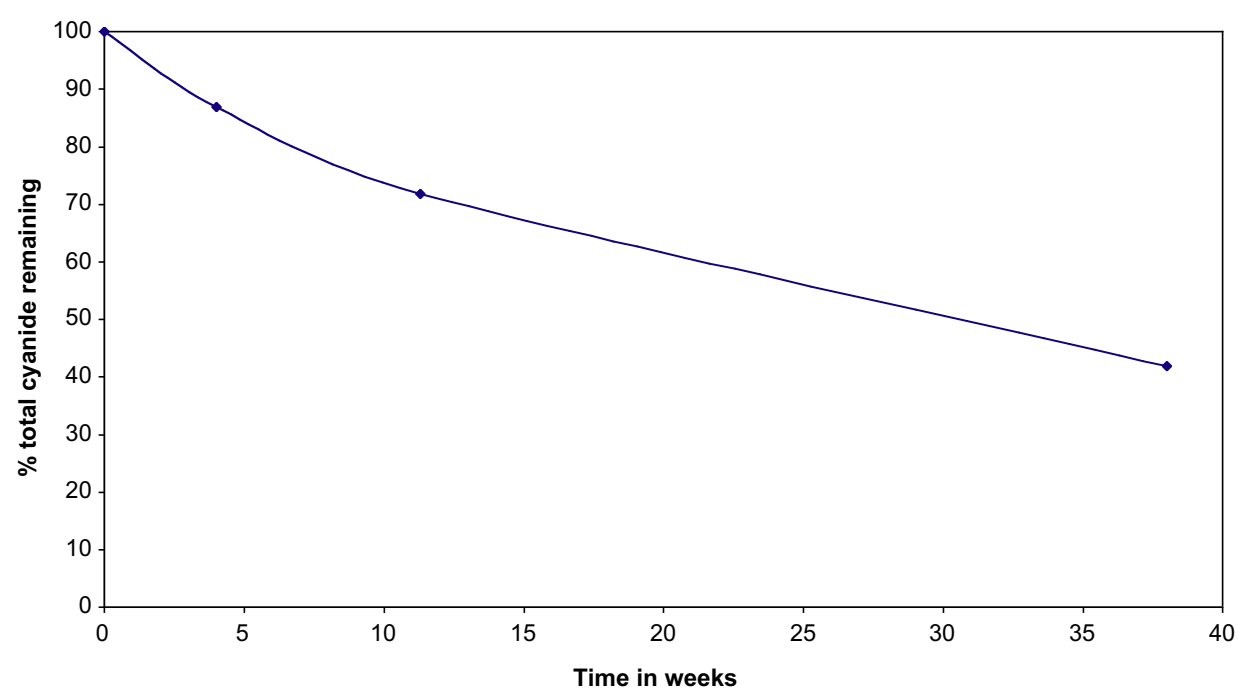

Fig. 1. \% Mean total cyanide remaining in five gari samples exposed to ambient laboratory conditions vs time in weeks.

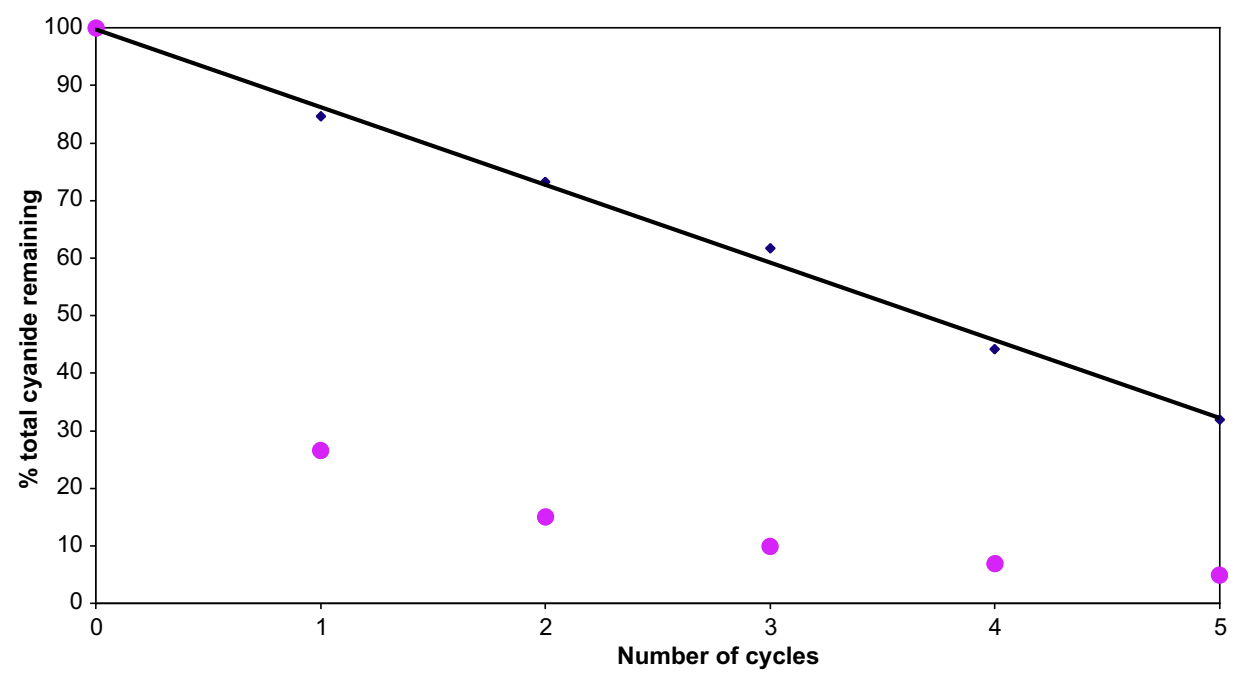

Fig. 2. \% Total cyanide remaining in wet gari 5 samples heated at $100{ }^{\circ} \mathrm{C}$ for 30 min intervals with water replacement over five cycles at pH $4.3(\diamond)$ and pH 6.9

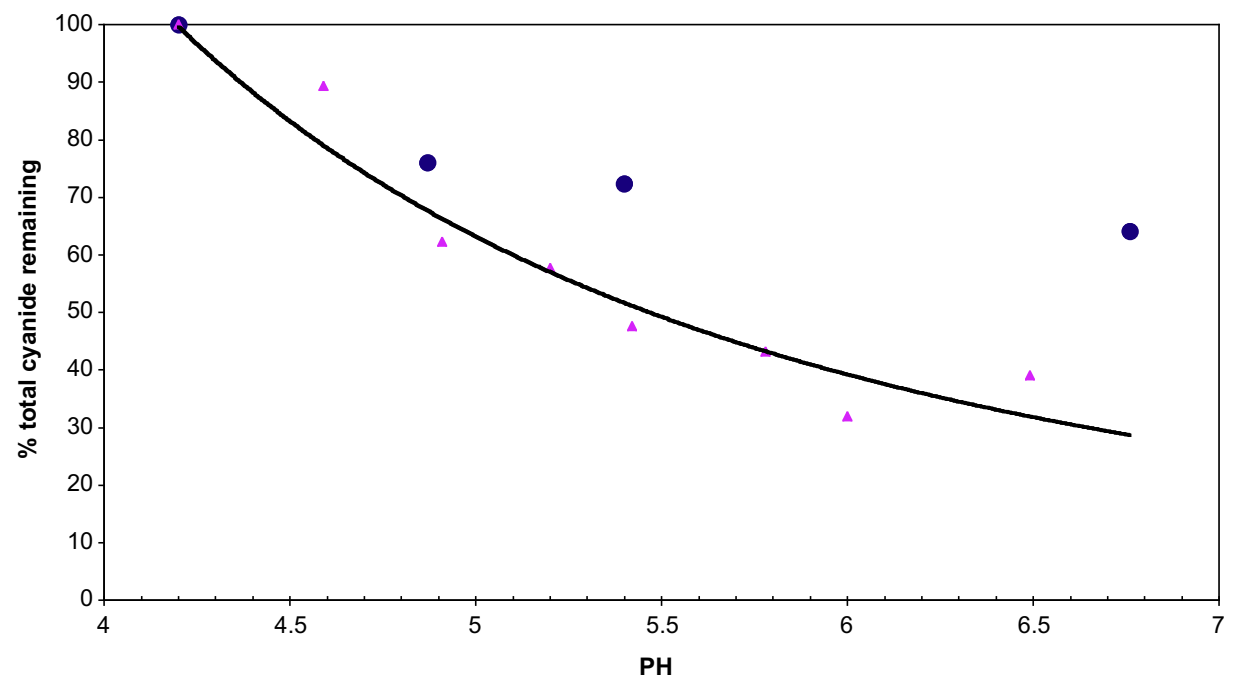

Fig. 3. \% Total cyanide remaining in wet buffered gari 2 samples after heating for $5 \mathrm{~h}$ at $30^{\circ} \mathrm{C}(\bullet)$ and $50{ }^{\circ} \mathrm{C}(\triangle)$ plotted against pH. 
cyanide remaining as $\mathrm{pH}$ is increased from $\mathrm{pH} 4.2$, where there is no loss.

At $30{ }^{\circ} \mathrm{C}$ only $30 \%$ of cyanide is lost at $\mathrm{pH} 6.5$, whereas extensive experiments with cassava flour samples show three- to sixfold losses of cyanide under similar conditions (Bradbury, 2006; Cumbana et al., 2007). This great difference in behaviour between gari and flour is probably due to the hard, gritty nature of roasted gari, and gelatinisation of starch which has fused particles together and restricted the transport of volatile $\mathrm{HCN}$, even when the gari particles are swollen by water. This explanation is consistent with the surprising increased cyanide content of larger gari particles (see Section 3.2).

As shown in Fig. 3 at $50{ }^{\circ} \mathrm{C}$ there is about twice as much cyanide lost as at $30^{\circ} \mathrm{C}$. These initial experiments show that in order to remove acetone cyanohydrin from wet gari the temperature of the treatment should be increased above the ambient temperature in the tropics and also the $\mathrm{pH}$ of the gari must be increased. There are limited possibilities of methods to increase the $\mathrm{pH}$ of gari for use in preparation of thick porridge. One possibility is by mixing gari with low cyanide cassava flour, which has a $\mathrm{pH}$ of approximately 6.5 (Bradbury, 2006; Cardoso et al., 2005). This method of increasing the $\mathrm{pH}$ by adding cassava flour is explored in Section 3.6.

\subsection{Cyanide loss from wet gari and wet gari/flour (1:1) mixtures}

The five samples of gari were mixed with an equal weight of two different flour samples and excess water, heated at $50{ }^{\circ} \mathrm{C}$ for $5 \mathrm{~h}$ and the loss of total cyanide monitored, see Section 2.2.2. The total cyanide content of the wet gari samples ranged from 1.7 to $8 \mathrm{ppm}$ and of wet MAus7(3) flour was $4.2 \mathrm{ppm}$ and of wet TMS 50395B flour was $10.6 \mathrm{ppm}$. Mixing gari with an equal weight of flour increased the $\mathrm{pH}$ of the mixture to $4.8-4.9$, and gari/flour $(1: 2)$ gave a $\mathrm{pH}$ of 5.1-5.2. The moisture content of the gari/flour (1:1) mixture decreased on heating at $50{ }^{\circ} \mathrm{C}$ from $60 \%$ at zero time to 20,15 and $8 \%$ after $4,4.5$ and $5 \mathrm{~h}$, respectively. The results in Table 2 show as expected, that in the absence of added flour, there is no loss of acetone cyanohydrin from wet gari at $\mathrm{pH} 4.2$, but with

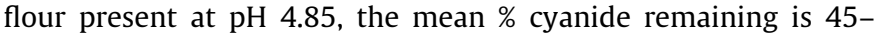
$66 \%$. Since the cyanide content of the flour and the gari samples are in the same range (1.7-10.6 ppm, see above) loss of cyanide from both gari and flour has contributed to the result. This is proved by the ca. $66 \%$ total cyanide remaining from gari at $\mathrm{pH}$ 4.85, see Fig. 3.

\subsection{Loss of cyanide from wet gari/flour (1:1) in the sun}

As shown in Table 3 wet gari did not lose cyanide after $4 \mathrm{~h}$ treatment in the sun. There was no breakdown of acetone cyanohydrin in wet gari 2 exposed to UV light from a Sunlamp for $2 \mathrm{~h}$. One hour exposure of a wet gari 2 sample to UV light at $254 \mathrm{~nm}$ from a Spectrolinker caused heating to $50-60^{\circ} \mathrm{C}$ with undesirable burning and yellowing of the sample and only a slight reduction in total cyanide content. Clearly, the acetone cyanohydrin present in wet

Table 2

\% Cyanide remaining in wet gari and wet gari/flour (1:1) samples after $5 \mathrm{~h}$ at $50^{\circ} \mathrm{C}$.

\begin{tabular}{lll}
\hline Experimental conditions & pH wet gari/flour $^{\mathrm{b}}$ & \% Cyanide remaining $^{\mathrm{b}}$ \\
\hline Wet gari, no flour & $4.23 \pm 0.03$ & $101 \pm 5$ \\
Wet gari/flour TMS50395B & $4.84 \pm 0.07$ & $45 \pm 7$ \\
Wet gari/flour MAus7(3) & $4.85 \pm 0.18$ & $66 \pm 17$ \\
\hline
\end{tabular}

\footnotetext{
a For detailed experimental conditions see Section 2.2.2.

b Each result with standard deviation is the mean of five gari samples.
}

Table 3

\% Cyanide remaining after gari/flour (1:1) samples treated in sun for $4 \mathrm{~h}^{\mathrm{a}}$

\begin{tabular}{lll}
\hline Experimental conditions & $\begin{array}{l}\text { Maximum temperature } \\
\left({ }^{\circ} \mathrm{C}\right) \text {, using iButton }\end{array}$ & $\begin{array}{l}\text { \% Cyanide remaining } \\
\text { after 4 h in sun }\end{array}$ \\
\hline $\begin{array}{l}\text { Wet gari 2, no flour } \\
\begin{array}{c}\text { Wet gari 1-5/flour } \\
\text { TMS50395B }\end{array}\end{array}$ & 41 & 94 \\
Wet gari 2/flour MAus7 & $53-55$ & $58 \pm 7$ \\
\end{tabular}

${ }^{\mathrm{a}}$ For detailed experimental conditions see Section 2.2.3. pH of all gari/flour (1:1) samples was measured at the end of each experiment and gave a mean value of $5.0 \pm 0.1$.

b Mean of 10 experiments.

gari is not broken down by UV light or by exposure in the sun for $4 \mathrm{~h}$.

Wet gari/flour (1:1) samples were heated in small Petri dishes in the sun for $4 \mathrm{~h}$ (see Section 2.2.3) on days when the maximum ambient temperature was about $30^{\circ} \mathrm{C}$ or higher. The temperature of the wet flour was monitored by metal iButtons either exposed directly to the sun or covered with a thin layer of gari/flour. The maximum temperature reached in any $4 \mathrm{~h}$ period of the exposed iButton as recorded in Table 3 varied from 41 to $55^{\circ} \mathrm{C}$. In general, the temperature of the covered iButton was $3-10^{\circ} \mathrm{C}$ lower than that of the open iButton. In one experiment the moisture content of the mixture dropped from $60 \%$ at the beginning to $6 \%$ at the end of the $4 \mathrm{~h}$ period in the sun. Experiments with $1 \mathrm{~g}$ samples of gari and flour were compared with the larger $5 \mathrm{~g}$ samples of gari and flour (see Section 2.2.3), and no difference was obtained in the \% cyanide remaining between the small and larger sample sizes. The thickness of the larger, wet gari/flour mixture was 5$10 \mathrm{~mm}$.

The results are recorded in Table 3 of exposure to the sun for $4 \mathrm{~h}$ of all samples of gari mixed with an equal weight of two different samples of flour and swollen with 1.5 times the weight of water. The average \% cyanide remaining over 10 experiments using flour TMS 50395B is 58\% and with flour MAus7 is $48 \%$, which agrees with the range of $45-66 \%$ from heating gari/flour (1:1) samples in an oven at $50{ }^{\circ} \mathrm{C}$ for $5 \mathrm{~h}$ (Table 2). This confirms the earlier conclusion that UV light from the sun does not cause decomposition of acetone cyanohydrin held within the wet gari/flour samples. This method of exposing wet gari/flour mixtures in the sun for about $4 \mathrm{~h}$, which reduces the total cyanide content by one half, is a simple method that could be used by rural people in West Africa. The method has not been tested with large samples as needed to feed a family, but work using the wetting method on cassava flour showed that cyanide losses were about the same for small and large flour samples, provided that the wet flour was allowed to stand in a thin layer $<1 \mathrm{~cm}$ thick, to allow hydrogen cyanide gas to escape readily (Cumbana et al., 2007).

\section{Conclusions}

It is found that the acetone cyanohydrin present in gari can be partially removed by swelling the gari by mixing with water, increasing its $\mathrm{pH}$ and raising the temperature of the wet gari. In these experiments the $\mathrm{pH}$ was increased by mixing gari with an equal weight of low cyanide cassava flour (but other methods may be discovered which do not destroy the desirable properties of gari as a food) and the temperature raised by exposing the wet mixture in a $1 \mathrm{~cm}$ thick layer in the sun for $4 \mathrm{~h}$. The total cyanide content of the mixture was reduced by about one half, which would reduce gari samples that average about $20 \mathrm{ppm}$ total cyanide (Cardoso et al., 2005) to10 ppm, the WHO safe level (FAO/ WHO, 1991). The treated mixture may be cooked in boiling water to produce thick porridge with reduced cyanide content. Adoption 
of this method may reduce the incidence of tropical ataxic neuropathy in Nigeria.

\section{Acknowledgements}

The authors thank Dr. Julie Cliff and Ms. Stacey Walker for obtaining the gari samples, Mr. Matthew Foster for preparing cyanide analysis kits, including the sensitive picrate papers and Mr. Malcolm Purdey for the experiments involving ultraviolet light.

\section{References}

Bradbury, J. H. (2006). Simple wetting method to reduce cyanogen content of cassava flour. Journal of Food Composition and Analysis, 19, 388-393.

Bradbury, J. H. (2009). Development of a sensitive picrate method to determine total cyanide and acetone cyanohydrin contents of gari from cassava. Food Chemistry, 113, 1329-1333.

Bradbury, J. H., \& Denton, I. C. (2010). Rapid wetting method to reduce cyanogen content of cassava flour. Food Chemistry, 121, 591-594.

Bradbury, J. H., \& Holloway, W. D. (1988). Chemistry of tropical root crops: Significance for nutrition and agriculture in the Pacific, Monograph No. 6 (p. 79) Canberra: Australian Centre for International Agricultural Research.

Cardoso, A. P., Ernesto, M., Cliff, J., Egan, S. V., \& Bradbury, J. H. (1998). Cyanogenic potential of cassava flour: Field trial in Mozambique of a simple kit. International Journal of Food Science and Nutrition, 49, 93-99.

Cardoso, A. P., Mirione, E., Ernesto, M., Massaza, F., Cliff, J., Haque, M. R., et al. (2005). Processing of cassava roots to remove cyanogens. Journal of Food Composition and Analysis, 18, 451-460.
Cumbana, A., Mirione, E., Cliff, J., \& Bradbury, J. H. (2007). Reduction of cyanide content of cassava flour in Mozambique by the wetting method. Food Chemistry, $101,894-897$.

FAO/WHO (1991). Joint FAO/WHO food standards programme, Codex Alimentarius Commission XII, Supplement 4. Rome, Italy: FAO.

Howlett, W. P., Brubaker, G. R., Mlingi, N., \& Rosling, H. (1990). Konzo, an epidemic upper motor neuron disease studied in Tanzania. Brain, 113, 223-235.

Karumba, A. K., Denton, I. C., \& Bradbury, J. H. (2009). Cyanide poisoning and konzo from cassava in South Kivu Province, DRC. CCDN News, 13, 2.

Madhusudanan, M., Menon, M. K., Ummer, K., \& Radhakrishnanan, K. (2008). Clinical and etiological profile of tropical ataxic neuropathy in Kerala, South India. European Neurology, 60, 21-26.

Nhassico, D., Muquingue, H., Cliff, J., Cumbana, A., \& Bradbury, J. H. (2008). Rising African cassava production, diseases due to high cyanide intake and control measures. Journal of the Science of Food and Agriculture, 88, 2043-2049.

Obilie, E. M., Tano-Debrah, K., \& Amoa-Awua, W. (2004). Souring and breakdown of cyanogenic glucosides during the processing of cassava into akyeke. International Journal of Food Microbiology, 93, 115-121.

Oluwole, O. S. A. Onabolu, A. O., Cotgreave, I. A., Rosling, H., Persson, A., \& Link, H. (2003). Incidence of endemic ataxic polyneuropathy and its relation to exposure to cyanide in a Nigerian community. Journal of Neurology, Neurosurgery and Psychiatry, 74, 1417-1422.

Onabolu, A. O., Oluwole, O. S. A., Rosling, H., \& Bokanga, M. (2002). Processing factors affecting the level of residual cyanohydrins in gari. Journal of the Science of Food and Agriculture, 82, 966-969.

Osuntokun, B. O. (1981). Cassava diet, chronic cyanide intoxication and neuropathy in Nigerian Africans. World Review Nutrition and Dietetics, 36, 141-173.

Osuntokun, B. O. (1994). Chronic cyanide intoxication of dietary origin and a degenerative neuropathy in Nigerians. Acta Horticulturae, 375, 311-321.

Sokari, T. G., \& Karibo, P. S. (1996). Short duration processing for high quality gari production. Journal of the Science of Food and Agriculture, 70, 427-432.

White, W. L. B., Mc Mahon, J. M., \& Sayre, R. T. (1994). Regulation of cyanogenesis in cassava. Acta Horticulturae, 375, 69-77. 